\title{
Balancing Socio-Emotional and Informational Considerations in Social Q\&A: The Case of Academia Stack Exchange (Paper)
}

\begin{abstract}
:
Many frequent social Q\&A sites to share information, with social and emotional support often important in continued use of these sites as resources for both information and socialization, but balancing these is not easy. We explored the socio-emotional motivations of users of Academia Stack Exchange and the influence of these on community coherence. Findings identified seven categories of socio-emotional motivations contributing positively or negatively to coherence. Academia SE focuses on being an information resource and on acculturation, learning, and translation, akin to legitimate peripheral participation, but empathetic concerns stress the necessity of further balancing socio-emotional and informational considerations.
\end{abstract}

\section{Introduction}

Many Internet users frequent social media sites to share information (Case \& Given, 2016), including social questioning-and-answering (social Q\&A) sites allowing users to ask and answer questions, share comments, and rate content (Choi, Kitzie, \& Shah, 2014; Worrall \& Oh, 2013). Users express a range of emotions in such use, with social and emotional support often important in their continued use of social Q\&A sites as resources for information and socialization (Choi et al., 2014; Kim, Oh, \& Oh, 2007, 2009; Kim \& Oh, 2009; Worrall \& Oh, 2013). Balancing these two uses, however, is not easy to perfect. Our exploration of the socio-emotional motivations of users of the Academia section of Stack Exchange (Academia SE) and the influence of these motivations on the potential coherence of communities around the site is evidence of this.

\section{Background}

Social support encompasses "the resources provided by other persons" (Cohen \& Syme, 1985, p. 4), including psychological, informational, physical, and emotional help that others may provide through social ties (Caplan, 1974). Support may guide resource, data, and information gathering, or instead provide a "sanctuary" of emotional comfort alleviating stress (p. 6); both can impact "health and well-being" (Cohen \& Syme, 1985, p. 4). Socio-emotional support and social ties often motivate users in their online information sharing (Ardichvili, 2008; Frost \& Masagli, 2008; Kazmer \& Haythornthwaite, 2001; McLure Wasko \& Faraj, 2000, 2005; Worrall, 2015), including on social Q\&A sites (Choi et al., 2014; Kim et al., 2007, 2009; Kim \& Oh, 2009; Worrall \& Oh, 2013). 
Raban and Harper (2008) identified perception of value, interaction, social cognition, information ownership, reciprocity, gratitude, access to technology, generalized exchange, reputation, status, norms, communality, payment, and social and cultural capital to motivate users' sharing on social Q\&A sites. Oh (2012) found altruism to be the most influential motivation in answering health-related questions on Yahoo! Answers, followed by enjoyment, efficacy, empathy, social engagement, learning, community interest, reputation, reciprocity, and personal gain. Oh and Syn (2015) tested these same ten motivations for sharing across five social media platforms, finding the nature of specific sites, topics, and users may well change which motivations are most common. Specific site features may also motivate, such as ranking by contribution level, expanded site privileges, and social reward structures (Shah, Oh, \& Oh, 2008).

As in other online communities (Preece \& Maloney-Krichmar, 2003; Rheingold, 2000), longitudinal participation occurs on social Q\&A sites (Gazan, 2010; Nam, Ackerman, \& Adamic, 2009). Such long-term information sharing may result in users establishing coherence (Star \& Griesemer, 1989) of social norms, social types, information values, and information behaviours (Jaeger \& Burnett, 2010) within and across the boundaries of socio- or informationcentric online communities, as observed elsewhere online (e.g. Star, Bowker, \& Neumann, 2003; Worrall, 2015). The translation and negotiation of norms, values, types, and behaviours can influence coherence, and users' socio-emotional motivations are a significant interacting factor in information sharing within this sociotechnical infrastructure.

\section{Methods}

This study addressed two exploratory research questions:

1. What social and emotional factors motivate users to ask questions, answer questions, and share information with other users on Academia SE?

2. Of these factors, do any contribute to the coherence of community, social norms, social types, information values, and information behaviours among users of Academia SE? If so, how?

Stack Exchange is one of the largest and most popular social Q\&A sites, with over five million users (Stack Exchange, 2018a); Academia SE is moderately popular with over 69,000 users and an average of 18 questions/day (Stack Exchange, 2018b). The site was chosen partly for its domain familiarity to the authors.

Three stages of data collection took place. First, content analysis looked at 100 Academia SE questions and their associated answers and comments as sampled at random from 1,000 recent questions. All three authors coded this data for socio-emotional motivations for sharing information (both from the literature and emerging from the data); occurrences of information sharing; and the presence of social norms, social types, information values, and boundaries. Second, a survey of Academia SE users used Likert scaled questions to ask users about these same motivations and characteristics, to which 48 responses were received. Finally, semistructured interviews were conducted with 12 users who completed the survey. These interviews examined both specific and general experiences of interviewees' questioning and answering, 
motivations for information sharing, and potential factors for coherence of communities. Survey responses and interviewees included users with a variety of levels of use of the site, although self-selection bias remains a potential limitation in the representativeness of these samples. The three authors discussed and overlapped their qualitative coding to help ensure the trustworthiness of the analysis (Lincoln \& Guba, 1985).

\section{Findings}

Seven categories of socio-emotional motivations were identified as most influential on Academia SE users' information sharingi.

1. Norms were the most common motivation, with users seeking guidance on how to act and behave in the academic community and exploring and suggesting ethical norms and questioning their variances in academia.

2. Communality was second most common, with many users sharing to lead to their greater acculturation into academic communities and for altruistic reasons. Explicit statements of communality were uncommon in the content analysis, but emerged in interviews.

3. Self-efficacy motivated some users to express their competency in egotistical ways, biased towards their own expertise, but others expressed better evidenced answers that offered multiple perspectives; our interviews also showed this range.

4. Enjoyment more positively motivated other users; interviewees told of their ongoing interest in sharing for reasons both informational and social.

5. Social cognition motivated users to learn more about social qualities and appearances in academia and academic relationships, often tied to acceptable normative behaviour.

6. Reputation and status were not the strongest motivations, but users did acknowledge their influence on academia and its norms.

7. A lack of empathy emerged from the data, as some answers were coupled with unnecessary bitterness, sarcasm, and circumstantial evidence despite the altruism of others. Many interviewees, particularly less frequent users, noted observing such led them to be uncomfortable, and actively tried to model greater empathy and altruism in their own sharing on Academia SE.

All of the factors above were found to contribute positively and/or negatively to the coherence of community, social norms, information values, and information behaviours. This coherence was only sometimes visible from the content analysis, but was more so from the survey results and interviewees' comments. Coherence around social norms and the translation of meaning and understanding into a community resource - a sort of data bank - was strongest in the survey, with little explicit coherence around information value. Interviews indicated much the same, but the negative motivations previously identified and the values they represented clearly had a corresponding negative impact on coherence for some of our interviewees who did not share these values. Acculturation, learning, and translation occurred despite these negative impacts.

\section{Discussion and Conclusions}

Our findings show a stronger role for norms, community, and self-efficacy, along with greater negativity and what is for some users a concerning lack of empathy, when compared with prior 
social Q\&A and social media research in other domains. In online communities focused on health social and emotional concerns are often prioritized over informational ones (e.g. Frost \& Masagli, 2008; Worrall \& Oh, 2013). In comparing Academia SE with these studies and those of other online communities, users have a stronger focus on the socio-informational components that drive their motivations, information sharing, and participation. Academia SE is positioned and used as an information resource and data bank for academics, and many users seem less interested in explicit, individualized empathy and socio-emotional support. This was particularly true for interviewees who were more active in the site's administration and thus its enforcement of norms. The coherence that occurs is focused on acculturation, learning, and translation, similar to legitimate peripheral participation (Lave \& Wenger, 1991); users are learning how to be part of the broader academic community and about its norms, values, and normative behaviours.

Some users interviewed, typically less frequent users of Academia SE, remain concerned by a tight focus on informational support and a relative lack of explicit, individualized empathy. Not every community will provide for the latter or in the same ways at the same levels. Nevertheless, interviewees implicit expectations around social norms, information value, and information behaviours from other communities led some to desire communality not just around information but also through affect and emotion. Academia SE does not display a perfect or fully accepted balance between informational and socio-emotional support; these implicit and sometimes invisible empathetic and communality considerations and values motivate some users and their desire to cohere with others sharing their norms, values, and behaviours (cf. Worrall, 2015). The broader norms and values of the Academia SE community and administration do not support explicit, individualized statements of empathy or communality; the collaborative translation, sharing, curation, and management of an information resource is more important than individuals' unique social and emotional contexts.

We believe further design, practice, and research work is necessary around the question of balancing empathy and socio-emotional considerations vs. informational ones in social Q\&A sites and other online communities. While some domains (e.g. health) will feature more explicit social and emotional support statements, what some users may see as the perpetuation of bitterness and self-efficacy to a fault could endanger a site like Academia SE both as a coherent community and as a source of data and information for academics, who are by no means resistant to anxieties, emotions, and wanting of communality and a sense of belonging. Users may receive social and emotional support from other communities within a broader contextual assemblage, but sites like Academia SE should still provide greater consideration of the invisible work (Star $\&$ Strauss, 1999) surrounding the often-implicit motivations and values of individuals and smaller groups while continuing to serve as highly informative and normative resources for a broader community. As with libraries (e.g. Phillips, 2017), library and information science should continue to further our theoretical and practical understanding of the diverse continuum of user experiences and the balance of socio-emotional and informational concerns in information sharing in online communities. 


\section{Acknowledgements}

We thank the anonymous reviewers for helpful feedback in improving this paper. This research was founded by a Support for the Advancement of Scholarship grant awarded to Worrall by the University of Alberta Faculty of Education.

\section{Reference List:}

Ardichvili, A. (2008). Learning and knowledge sharing in virtual communities of practice: Motivators, barriers, and enablers. Advances in Developing Human Resources, 10, 541-554. https://doi.org/10.1177/1523422308319536

Caplan, G. (1974). Support systems and community mental health: Lectures on concept development. New York, NY: Behavioral Publications.

Case, D. O., \& Given, L. M. (2016). Looking for information: A survey of research on information seeking, needs, and behavior (4th ed.). Bingley, UK: Emerald.

Choi, E., Kitzie, V., \& Shah, C. (2014). Investigating motivations and expectations of asking a question in social Q\&A. First Monday, 19(3). Retrieved from http://firstmonday.org/ojs/ index.php/fm/article/view/4830

Cohen, S., \& Syme, S. L. (1985). Issues in the study and application of social support. In Social support and health (pp. 3-22). Orlando, FL: Academic Press.

Frost, J. H., \& Massagli, M. P. (2008). Social uses of personal health information within PatientsLikeMe, an online patient community: What can happen when patients have access to one another's data. Journal of Medical Internet Research, 10(3). https://doi.org/10.2196/ jmir.1053

Gazan, R. (2010). Microcollaborations in a social Q\&A community. Information Processing and Management, 46, 693-702. https://doi.org/10.1016/j.ipm.2009.10.007

Jaeger, P. T., \& Burnett, G. (2010). Information worlds: Behavior, technology, and social context in the age of the Internet. New York, NY: Routledge.

Kazmer, M. M., \& Haythornthwaite, C. (2001). Juggling multiple social worlds: Distance students online and offline. American Behavioral Scientist, 45, 510-529. https://doi.org/10.1177/ 00027640121957196

Kim, S., Oh, J. S., \& Oh, S. (2007). Best-answer selection criteria in a social Q\&A site from the user oriented relevance perspective. In A. Grove (Ed.), Proceedings of the 70th ASIS\&T Annual Meeting: Joining research and practice: Social computing and information science. Silver Spring, MD: American Society for Information Science and Technology. https://doi.org/10.1002/ meet.1450440256 
Kim, S., \& Oh, S. (2009). Users' relevance criteria for evaluating answers in a social Q\&A site. Journal of the American Society for Information Science and Technology, 60, 716-727. https:// doi.org/10.1002/asi.21026

Kim, S., Oh, S., \& Oh, J. S. (2009). Evaluating health answers in a social Q\&A site. In A. Grove (Ed.), Proceedings of the 72nd ASIS\&T Annual Meeting: Information opportunities in a pluralistic world. Silver Spring, MD: American Society for Information Science and Technology. https://doi.org/10.1002/meet.2008.14504503134

Lave, J., \& Wenger, E. (1991). Situated learning: Legitimate peripheral participation. Cambridge, UK: Cambridge University Press.

Lincoln, Y. S., \& Guba, E. G. (1985). Establishing trustworthiness. In Naturalistic inquiry (pp. 289-331). Newbury Park, CA: Sage.

McLure Wasko, M., \& Faraj, S. (2000). "It is what one does": Why people participate and help others in electronic communities of practice. The Journal of Strategic Information Systems, 9, 155-173. https://doi.org/10.1016/S0963-8687(00)00045-7

McLure Wasko, M., \& Faraj, S. (2005). Why should I share? Examining social capital and knowledge contribution in electronic networks of practice. MIS Quarterly, 29, 35-57.

Nam, K. K., Ackerman, M. S., \& Adamic, L. A. (2009). Questions in, knowledge iN? A study of Naver's question answering community. In D. R. Olsen, Jr., \& R. B. Arthur (Eds.), Proceedings of the 27th international conference on Human Factors in Computing Systems (CHI '09, pp. 779-788). New York, NY: ACM. https://doi.org/10.1145/1518701.1518821

Oh, S. (2012). The characteristics and motivations of health answerers for sharing information, knowledge, and experiences in online environments. Journal of the American Society for Information Science and Technology, 63, 543-557. https://doi.org/10.1002/asi.21676

Oh, S., \& Syn, S. Y. (2015). Motivations for sharing information and social support in social media: A comparative analysis of Facebook, Twitter, Delicious, YouTube, and Flickr. Journal of the Association for Information Science and Technology, 66, 2045-2060. https://doi.org/10.1002/ asi. 23320

Phillips, A. (2017). Understanding empathetic services: The role of empathy in everyday library work. Journal of Research on Libraries and Young Adults, 8(1). Retrieved from http:// www.yalsa.ala.org/jrlya/wp-content/uploads/2017/07/Phillips_Understanding-Empathetic_ final.pdf

Preece, J., \& Maloney-Krichmar, D. (2003). Online communities: Focusing on sociability and usability. In J. A. Jacko \& A. Sears (Eds.), The human-computer interaction handbook (pp. 596620). Mahwah, NJ: Lawrence Erlbaum Associates. 
Raban, D. R., \& Harper, F. M. (2008). Motivations for answering questions online. In D. Caspi \& T. Samuel-Azran (Eds.), New Media and Innovative Technologies. Beersheba, Israel: BenGurion University of the Negev Press. Retrieved from http://citeseerx.ist.psu.edu/viewdoc/ download?doi=10.1.1.119.1962\&rep $=$ rep1\&type $=$ pdf

Rheingold, H. (2000). The virtual community: Homesteading on the electronic frontier (revised ed.). Cambridge, MA: MIT Press.

Shah, C., Oh, J. S., \& Oh, S. (2008). Exploring characteristics and effects of user participation in online social Q\&A sites. First Monday, 13(9). Retrieved from http://www.uic.edu/htbin/cgiwrap/ bin/ojs/index.php/fm/article/view/2182/2028

Stack Exchange. (2018a). About. In Stack Exchange. Retrieved from https://stackexchange.com/ about

Stack Exchange. (2018b). All sites. In Stack Exchange. Retrieved from https:// stackexchange.com/sites

Star, S. L., Bowker, G. C., \& Neumann, L. J. (2003). Transparency beyond the individual level of scale: Convergence between information artifacts and communities of practice. In A. P. Bishop, N. A. Van House, \& B. P. Buttenfield (Eds.), Digital library use: Social practice in design and evaluation (pp. 241-269). Cambridge, MA: MIT Press.

Star, S. L., \& Griesemer, J. R. (1989). Institutional ecology, 'translations' and boundary objects: Amateurs and professionals in Berkeley's Museum of Vertebrate Zoology, 1907-39. Social Studies of Science, 19, 387-420. https://doi.org/10.1177/030631289019003001

Star, S. L., \& Strauss, A. (1999). Layers of silence, arenas of voice: The ecology of visible and invisible work. Computer Supported Cooperative Work, 8, 9-30. https://doi.org/10.1023/ A:1008651105359

Worrall, A. (2015). "Like a real friendship": Translation, coherence, and convergence of information values in LibraryThing and Goodreads. In G. Olson (Ed.), iConference 2015 proceedings. Champaign, IL: iSchools. Retrieved from http://hdl.handle.net/2142/73641

Worrall, A., \& Oh, S. (2013). The place of health information and socio-emotional support in social questioning and answering. Information Research, 18(3). Retrieved from http:// informationr.net/ir/18-3/paper587.html

Worrall, A., Osolen, R., \& Cappello, A. (2017). "How do I tell my advisor?": Socio-emotional motivations for information sharing in Academia Stack Exchange. In A. Gruzd, J. Jacobson, \& P. Mai (Chairs), Proceedings of the 8th international conference on Social Media and Society (SMSociety17), Toronto, ON, July 28-30, 2017. New York, NY: ACM.

\footnotetext{
${ }^{\mathrm{i}}$ A preliminary version of this analysis was shared in Worrall, Osolen, and Cappello (2017).
} 